\title{
Differences in Breast Density Awareness, Knowledge, and Plans
}

$\mathrm{J}$ Gen Intern Med 35(8):2473

DOI: $10.1007 / \mathrm{s} 11606-020-05840-\mathrm{z}$

(c) Society of General Internal Medicine 2020

$\mathrm{M}$ s. Pushkin and Dr. Berg further emphasize a limitation we noted in our paper, "Differences in Breast Density Awareness, Knowledge and Plans on State Legislation Status and Sociodemographic Characteristics," which is that states vary in the quality and quantity of information included in breast density notifications, and we did not have sufficient statistical power in our sample to examine the impact of such variations directly. We agree with Ms. Pushkin and Dr. Berg that it will be critically important for the Food and Drug Administration (FDA) to determine appropriate content requirements for the federally mandated notification as well as wording that is understandable to all women and leads to the desired outcomes: informing women about the risks of breast density and increased utilization of supplemental screening for women for whom it is appropriate. We have made this suggestion to the FDA and have provided them with the results of our study.

The Letter seems to imply that women's primary source of information about breast density will be from the federally mandated notifications. We hope this will not be the case, nor the explicit purpose of legislation regulating breast density notifications. Instead, we hope that women who receive dense breast notifications have higher rates of conversation with their personal providers about breast density and their overall risk for breast cancer (not just supplemental screening, etc.). We hope that Ms. Pushkin and Dr. Berg agree that women should be making breast screening decisions in consultation with a medical provider, not on the basis of a breast density notification. Our prior work suggests that women prefer these conversations with their providers in order to understand the implications of breast density on their own health. ${ }^{1}$

Published online May 11, 2020
We agree with Ms. Pushkin and Dr. Berg that "To understand the impact of personal notification, an analysis of state inform laws that do provide full information in the form of personal notification of density and information on masking, risk and supplemental screening, compared to states with no DBN, would be helpful." Future research should address this important question.

Sincerely,

Nancy R Kressin, PhD

Jolie B. Wormwood, PhD

Tracy A. Battaglia, MD, MPH

Christine M. Gunn, PhD

Nancy R. Kressin, $\mathrm{PhD}$

Tracy A. Battaglia, MD, MPH

Christine M. Gunn, PhD

Department of Medicine, Boston University School of

Medicine, Boston, MA, USA

Jolie B. Wormwood, $\mathrm{PhD}$

Department of Psychology, University of New Hampshire, Durham, NH, USA

Corresponding Author: Nancy R. Kressin, PhD; Department of Medicine, Boston University School of Medicine Boston, MA, USA (e-mail: nkressin@bu.edu).

\section{Compliance with Ethical Standards:}

Conflict of Interest: The authors have no conflicts to report.

\section{REFERENCE}

1. Gunn, C., Battaglia TA, Paasche-Orlow MK, West AK, Kressin NR., Women's Perceptions of Dense Breast Notifications: "So what is that supposed to mean?”. Patient Educ Couns, 2018. 101(6): p. 1123-1129.

Publisher's Note: Springer Nature remains neutral with regard to jurisdictional claims in published maps and institutional affiliations. 